\title{
Stroke: Medium and long-term mortality and associated factors in French-speaking West Africa, case of Benin
}

\author{
Dieu Donné Gnonlonfoun ${ }^{1 *}$, Constant Adjien ${ }^{1}$, Paul Macaire Ossou-Nguiet ${ }^{2}$, Isaac Avlessi ${ }^{1}$, \\ Gérald Goudjinou $^{1}$, Octave Houannou ${ }^{1}$, Jocelyn Acakpo ${ }^{3}$, Dismand Houinato ${ }^{1}$, Gilbert Dossou Avode ${ }^{1}$ \\ ${ }^{1}$ Neurology Department, CNHU-HKM, Cotonou, Benin \\ ${ }^{2}$ Neurology Department, CHU, Brazzaville, Congo \\ ${ }^{3}$ Epidemiology Institute FSS/UAC, Cotonou, Benin \\ Email: * dignon2002@yahoo.fr
}

Received 18 December 2013; revised 8 January 2014; accepted 16 January 2014

Copyright (C 2014 Dieu Donné Gnonlonfoun et al. This is an open access article distributed under the Creative Commons Attribution License, which permits unrestricted use, distribution, and reproduction in any medium, provided the original work is properly cited. In accordance of the Creative Commons Attribution License all Copyrights (c) 2014 are reserved for SCIRP and the owner of the intellectual property Dieu Donné Gnonlonfoun et al. All Copyright @ 2014 are guarded by law and by SCIRP as a guardian.

\section{ABSTRACT}

Introduction: Stroke is the leading cause of mortality and physical disability in sub-Saharan Africa. Objective: Determining medium-term and long-term mortality for stroke and identifying associated factors. Method: It consists in a cross-sectional, prospective, descriptive and analytical study that was conducted from April 1 to August 31, 2013 in the Neurology Department of CNHU-HKM in Cotonou. It involved patients who have known stroke for at least 6 months, and were all admitted and discharged later on. The disease survivors were re-contacted and examined again at home or at hospital. Then, the number of deceased was systematically recorded with precision of death time-limit. Results: The overall mortality rate was $29 \%$. Mortality was higher with patients over 70 years with a frequency of $57.1 \%$. The medium-term mortality rate was $25 \%$ against $4 \%$ for long-term. The average time-limit for death occurrence after the vascular incident was 7 months \pm 6.4 months. Prognostic factors of mortality were: the age of the patient $\left(\mathrm{IC}_{95 \%}=7.73[1.49-39.99], \mathrm{p}=\mathbf{0 . 0 1 5}\right)$, marital status $\left(\mathrm{IC}_{95 \%}=\mathbf{0 . 2 7}[0.08\right.$ to 0.94$\left.], \mathrm{p}=\mathbf{0 . 0 3 9}\right)$ and the presence of aphasia $\left(\mathrm{IC}_{95 \%}=5.52[1.45\right.$ to 20.94 ], $p=0.012)$. Conclusion: Stroke mortality still remains significant, even after the patients have been discharged from hospital. A good psychological family support and efficient aphasia coverage are essential for its reduction.

\section{KEYWORDS}

Mortality; Stroke; Medium Term; Long Term;

\footnotetext{
*Corresponding author.
}

\section{Cotonou}

\section{INTRODUCTION}

Stroke is the leading cause of hospitalization in neurology departments [1-3]. According to World Health Organization, it is defined as "the presence of clinical signs of cerebral dysfunction occurring rapidly, for 24 hours or longer or leading to death, without any other apparent cause but that of vascular origin." This is the leading cause of death [4,5] and physical disability [2] in subSaharan Africa. Hypertension, diabetes, obesity and hyperlipidemia are known as factors associated with the occurrence of stroke [5]. But do they constitute mortality prognostic factors in medium and long term? Knowing these mortality prognostic factors in the neurology department of Benin University Hospital Hubert Maga Koutougou (CNHU-HKM) of Cotonou will help to take preventive and remedial measures so as to reduce the mortality rate of this disease. To this end, this study was initiated and aims at determining medium-term and longterm stroke mortality and identifying associated factors.

\section{METHOD}

The method consisted in a cross-sectional, prospective descriptive and analytical study conducted from April $1^{\text {st }}$, 2013 to August 31, 2013 at Benin University Hospital Hubert Maga koutoukou in Cotonou. Benin is a French Speaking country in West Africa (Figure 1), sharing borders with Nigeria on the east. It boasts of 9 million inhabitants and an area of $112.622 \mathrm{~km}^{2}$. The population subject to study consisted of patients suffering from stroke at least for the past 6 months. The sample size was 


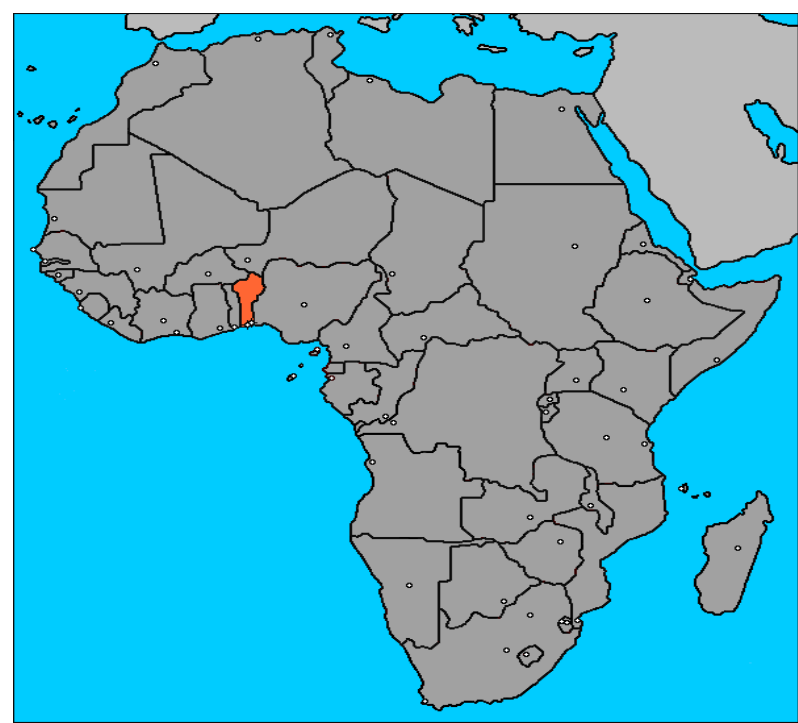

Figure 1. Position of Benin in Africa.

calculated using Daniel Schwartz formulae $\mathrm{n}=\mathrm{Z} \alpha^{2} \mathrm{pq} / \mathrm{i}^{2}$ $=96$ with $\mathrm{p}=48.3 \%$ (stroke prevalence of in the neurology department at CNHU-HKM [3], $\alpha=5 \%$ and I $=10 \%$. But the total number of subjects enrolled in the study period was 100 . During the study period, we performed a systematic enrollment of all patients who met the inclusion criteria and consented to participate in the study, up to the number expected.

\section{1) Inclusion criteria}

-Having suffered from stroke and been treated in the Department of Neurology;

-Having been suffering from stroke for at least 6 months;

-Having provided one's contacts in the medical record during hospitalization.

\section{2) Exclusion criteria}

-Any patient with a meningeal hemorrhage, cerebral venous thrombosis or a neurological deficit associated with head injury or brain tumor or other cause;

-Exception of brain scan.

\section{3) Diagnostic criteria}

In this study,

-Stroke diagnosis is made on the basis of a neurological deficit of sudden fitting and the outcome of brain scan;

-The medium-term is defined as a period longer than 6 months and less than 12 months after stroke occurrence;

-The long term is defined as a period beyond 12 months after stroke occurrence.

\section{4) Collection modalities}

From the patient folder and database made available by the service, all patients having suffered from stroke and meeting the inclusion criteria were identified up to the sample size. Only those who survived stroke and were discharged after hospitalization were contacted via telephone. Those who were still alive were re-examined either at hospital or in their home on appointment basis. Deaths rate were systematically recorded with precision of death time-limit. A clinical examination of the patient was then carried out together with a set of questionnaires. The data were supplemented by the analysis of patient medical records.

\section{5) The variables studied were}

Dependent variable: mortality

Independent variables:

-The socio-demographic data (age, gender, ethnicity, occupation, marital status, monthly income in dollar US)

-Past record (hypertension, diabetes, hyperlipidemia, heart disease).

-The patient's lifestyle (alcohol, tobacco, inactivity, others)

-Data available when stroke occurred: date of stroke occurrence, stroke type, stroke topography, hemi-corpus in deficit, hypertension, deficit type, aphasia, consciousness disorder, seizures, metabolic disorders, time-limit between stroke occurrence and the day the survey was conducted, duration of hospitalization, recurrence after hospitalization, physiotherapy and any other rehabilitation act (motor, speech therapy, occupational therapy)

-Current clinical data: blood pressure, BMI, mobility.

\section{6) Data processing and analysis}

Data processing was conducted through EPI-DATA. Audit and data analysis were done using statistics software STATA/IC 11.0. A descriptive analysis was completed with regard to the variables which were studied. So, as far as qualitative variables were concerned, frequencies and proportions were determined. Either chi2 or FISHER test was used if only expected values are lower than 5. For quantitative values, averages together with their typical gaps, medians, minima and maxima have all been described. STUDENT test was utilized for comparisons. The study of associated factors was conducted using logistical regression model in unvaried and multi-varied analyses. The multi-varied analysis was carried out by inserting into the model all variables, of which $\mathrm{p}$ value in unvaried analysis is less or equal to $20 \%$ because of the exploratory nature of the study. The breakeven point in terms of significance was $5 \%$ and confidence gap rated at $95 \%$.

\section{7) Ethical considerations}

Each patient or his/her next of kin submitted a written letter of consent upon explanation of the study objective and modalities.

\section{RESULTS}

\section{1) Mortality characteristics}

As the Figure 2 illustrates, 29 patients passed away out of the 100 patients who meet the inclusion criteria 


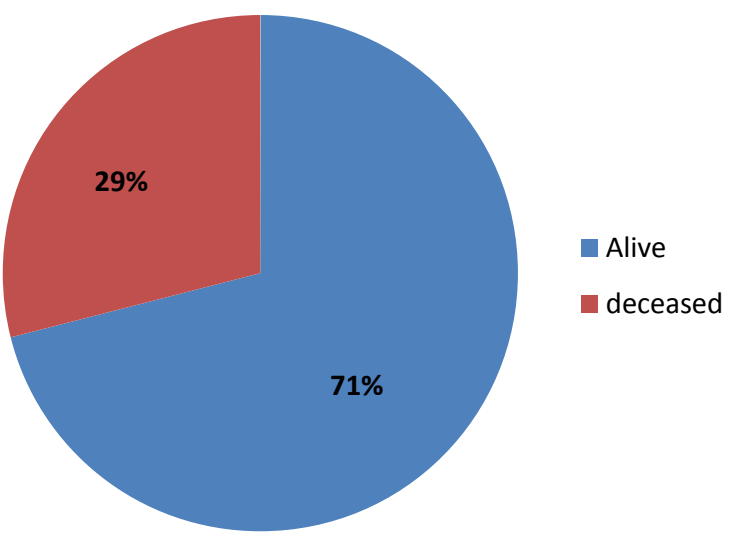

Figure 2. Rate of overall stroke mortality, Cotonou 2013.

and were contacted later on. Mortality rate was higher with patients over 70 years, frequency being $57.1 \%$ ( $<$ $0.001)$. Table 1 shows mortality classification as per age. Stroke patients mortality rate in short term (25\%) is higher than the rate in long term $(4 \%) p=0.0001$. These data are summarized in Figure 3. The average time-limit before death occurrence upon stroke is 7 months \pm 6.4 months. Figure 4 illustrates mortality rate as per timelimit between stroke and death occurrence. Mortality within ischemic stroke patients was 32.4\%. Table 2 shows death classification as per type of stroke.

Frequency of medium term hemorrhagic stroke deaths happening between 3 and 6 months is $57.1 \%$, and $40.9 \%$ of medium term ischemic stroke deaths occurred between 6 and 12 months. Figure 5 shows classification of stroke mortality as per time-limit.

2) Factors associated with mortality, outcome to unvaried analysis.

Age above 70 years $\left(\mathrm{IC}_{95 \%}=8[1.91-33.54], \mathrm{p}<\right.$ $0.001)$ and marital status $\left(\mathrm{IC}_{95 \%}=0.30\right.$ [0.12 - 0.73], $\mathrm{p}=$ $0.007)$ were the socio-demographic factors associated with stroke mortality. Table 3 sums up these data. Concerning past records $\mathrm{BP}\left(\mathrm{IC}_{95 \%}=2.3[1.73-4.21]\right.$, $\mathrm{p}=$ 0.03), diabetes $\left(\mathrm{IC}_{95 \%}=4.81[1.68-13.76], \mathrm{p}=0.002\right)$ and hyperlipidemia $\left(\mathrm{IC}_{95 \%}=11.2[1.19-105.0] \mathrm{p}=0.01\right)$ were associated with mortality as shown in Table 4. Clinically, the importance of motion deficit $\left(\mathrm{IC}_{95 \%}=0.38\right.$ [0.14 - 0.99], $\mathrm{p}=0.04$ ) and the presence of aphasia ( $\mathrm{IC}_{95 \%}$ $=2.58[0.98-6.81], \mathrm{p}=0.04$ ) were associated with stroke mortality. Table 5 illustrates these data.

3) Prognostic factors of stroke mortality in medium and long term, outcome to multivariate analysis.

After a multi-varied analysis of associated variables in unvaried analysis, those which were individually associated with mortality were: patient's age at stroke occurrence $\left(\mathrm{IC}_{95 \%}=7.73\right.$ [1.49 -39.99$\left.], \mathrm{p}=0.015\right)$, marital status $\left(\mathrm{IC}_{95 \%}=0.27[0.08-0.94], \mathrm{p}=0.039\right)$ and the presence of aphasia $\left(\mathrm{IC}_{95 \%}=5.52[1.45-20.94], \mathrm{p}=\right.$ 0.012). Table 6 shows these data.

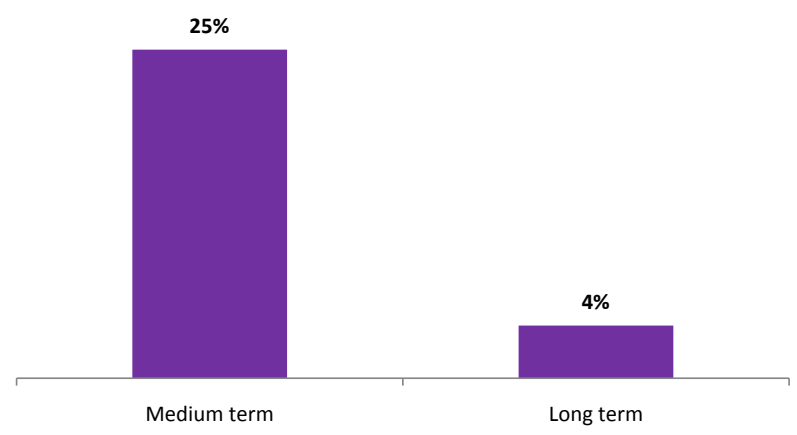

Figure 3. Stroke mortality rate as per time-limit.

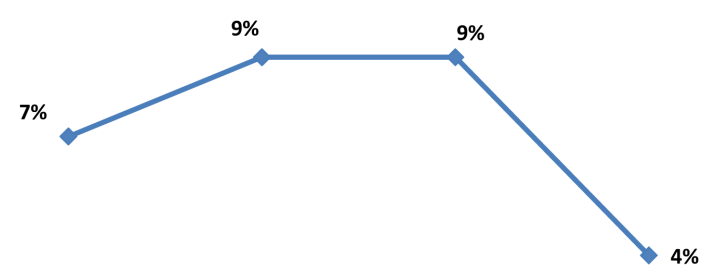

$$
<3 \text { months [3-6 months] [6-12 months] } \geq 12 \text { months }
$$

Figure 4. Mortality as per the time-limit between stroke occurrence and death, Cotonou 2013.

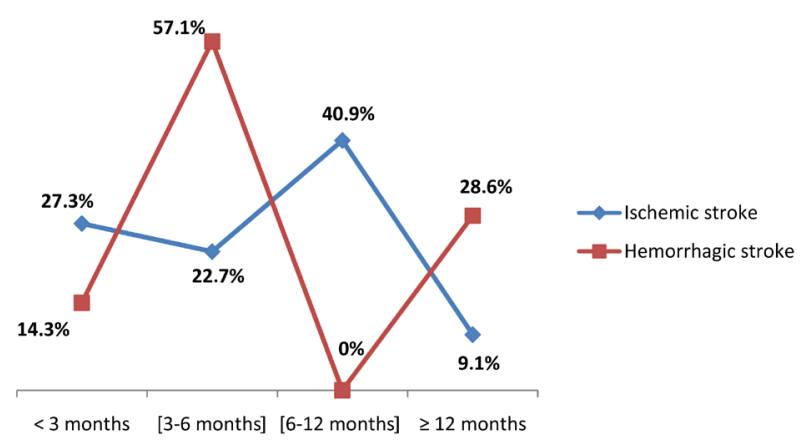

Figure 5. Classification of stroke mortality rate as per time-limit, Cotonou 2013.

Table 1. Mortality as per age, Cotonou 2013.

\begin{tabular}{cccc}
\hline Age (years) & Living n (\%) & Death n (\%) & Total \\
\hline$<50$ years & $18(85.7)$ & $3(14.3)$ & 21 \\
{$[50-60]$} & $27(93.1)$ & $2(6.9)$ & 29 \\
{$[60-70]$} & $14(63.6)$ & $8(36.4)$ & 22 \\
$\geq 70$ ans & $12(42.9)$ & $16(57.1)$ & 28 \\
Total & $\mathbf{7 1}$ & $\mathbf{2 9}$ & $\mathbf{1 0 0}$ \\
\hline
\end{tabular}

$\mathrm{p}<0.001$.

\section{DISCUSSION}

It was a cross-sectional and prospective study with de- 
Table 2. Death classification as per type of stroke, Cotonou 2013.

\begin{tabular}{cccc}
\hline Type of Stroke & Living n (\%) & Death $\mathbf{n ( \% )}$ & Total \\
\hline Ischemic & $47(68.1)$ & $22(32.4)$ & 69 \\
Hemorrhagic & $24(77.4)$ & $7(22.6)$ & 31 \\
Total & $\mathbf{7 1 ( 7 1 . 0 )}$ & $\mathbf{2 9 ( 2 9 . 0 )}$ & $\mathbf{1 0 0}$ \\
\hline
\end{tabular}

Table 3. Socio-demographic factors associated with stroke mortality rate, Cotonou 2013.

\begin{tabular}{|c|c|c|c|c|}
\hline $\begin{array}{c}\text { Socio-demographic } \\
\text { variables }\end{array}$ & Total & $\begin{array}{l}\text { Death } \\
\text { n (\%) }\end{array}$ & RC $\left[\right.$ IC $\left._{95 \%}\right]$ & p Value \\
\hline Age (year) & & & & $<0.001^{*}$ \\
\hline Below 50 & 21 & $3(14.3)$ & 1 & \\
\hline Between 50 and 60 & 29 & $2(6.9)$ & 0.44 [0.07 - 2.93] & \\
\hline Between 60 and 70 & 22 & 8 (36.7) & $3.43[0.76-15.36]$ & \\
\hline Over 70 & 28 & $16(57.1)$ & $8[1.91-33.54]^{*}$ & \\
\hline Sex & & & & 0.209 \\
\hline Male & 58 & $14(24.1)$ & 1 & \\
\hline Female & 42 & 15 (35.7) & $1.75[0.73-4.18]$ & \\
\hline Marital status & & & & $0.007^{*}$ \\
\hline Single & 38 & 17 (44.7) & 1 & \\
\hline Married life & 62 & $12(19.3)$ & $0.30[0.12-0.73]$ & \\
\hline Lifestyle & & & & 0.395 \\
\hline Alcohol & 50 & $13(13.0)$ & 1 & \\
\hline Smoking & 6 & $2(33.3)$ & $1.42[0.23-8.71]$ & \\
\hline Sedentary life & 35 & $14(40.0)$ & $1.90[0.75-4.79]$ & \\
\hline P Profession & & & & 0.12 \\
\hline Civil servant & 27 & $5(18.5)$ & 1 & \\
\hline Private sector worker & 12 & $2(16.7)$ & 0.88 [0.14 - 5.33] & \\
\hline Craftsman & 13 & $2(15.4)$ & $0.80[0.13-4.80]$ & \\
\hline Housewife & 33 & $14(42.4)$ & 3.24 [0.98 - 10.67] & \\
\hline Retired employee & 14 & $6(42.9)$ & 3.30 [0.78 - 13.87] & \\
\hline Ethnicity & & & & 0.69 \\
\hline Fon & 40 & $12(30.0)$ & 1 & \\
\hline Goun & 30 & $10(33.3)$ & $1.17[0.42-3.22]$ & \\
\hline Mina & 9 & $1(11.1)$ & $0.29[0.03-2.59]$ & \\
\hline Yoruba & 8 & $5(62.5)$ & 3.89 [0.80 - 18.93] & \\
\hline Others & 13 & $1(7.7)$ & $0.19[0.02-1.66]$ & \\
\hline
\end{tabular}

*Significant results.
Table 4. Past records associated with stroke mortality, Cotonou 2013.

\begin{tabular}{ccccc}
\hline Past records & Total & Deaths n (\%) & RC [ IC $_{95 \%}$ ] & p Value \\
\hline High BP & & & & $0.03^{*}$ \\
No high BP & 10 & $0(0)$ & 1 & \\
High BP & 90 & $29(29.0)$ & $2.3[1.73-4.21]$ & \\
Diabetes & & & 1 & $0.002^{*}$ \\
No diabetes & 81 & $18(22.3)$ & 1 & \\
Diabetes & 19 & $11(57.9)$ & $4.81[1.68-13.76]$ & \\
Hyperlipidemia & & & & $0.01^{*}$ \\
No & 95 & $25(26.3)$ & 1 & 0.28 \\
Yes & 5 & $4(80.0)$ & $11.2[1.19-105.0]$ & \\
Cardiopathy & & & & \\
No & 91 & $27(27.5)$ & 1 & \\
Yes & 9 & $4(44.4)$ & $2.11[0.52-8.51]$ & \\
& & & &
\end{tabular}

"Significant results.

Table 5. Clinical factors associated with stroke mortality rate, Cotonou 2013.

\begin{tabular}{|c|c|c|c|c|}
\hline Factors & Total & $\begin{array}{l}\text { Death } \\
\text { n (\%) }\end{array}$ & RC $\left[\mathrm{IC}_{95 \%}\right]$ & p Value \\
\hline Handicapped side & & & & 0.86 \\
\hline Right & 67 & 20 (29.9) & 1 & \\
\hline Left & 32 & $9(28.1)$ & $0.92[0.36-2.33]$ & \\
\hline Level of handicap & & & & $0.04^{*}$ \\
\hline Paralysis & 60 & $22(36,7)$ & 1 & \\
\hline Paresis & 39 & 7 (17.9) & 0.38 [0.14 - 0.99] & \\
\hline Mental disorder & & & & 0.12 \\
\hline No & 60 & 14 (23.3) & 1 & \\
\hline Yes & 40 & 15 (37.5) & $1.97[0.82-4.73]$ & \\
\hline Aphasia & & & & $0.04^{*}$ \\
\hline No & 39 & 7 (17.9) & 1 & \\
\hline Yes & 61 & $22(36.1)$ & $2.58[0.98-6.81]$ & \\
\hline Sphincter disorders & & & & 0.10 \\
\hline No & 85 & 22 (25.9) & 1 & \\
\hline Yes & 15 & 7 (46.7) & $2.51[0.81-7.71]$ & \\
\hline Metabolic disorder & & $\mathrm{Q}$ & & 0.08 \\
\hline No & 74 & 19 (25.7) & 1 & \\
\hline Yes & 17 & $8(47.1)$ & $2.57[0.87-7.62]$ & \\
\hline Recidivism & & & & 0.24 \\
\hline No & 94 & $26(27.7)$ & 1 & \\
\hline Yes & 6 & $3(50.0)$ & $2.62[0.49-13.79]$ & \\
\hline
\end{tabular}

*Significant results. 
Table 6. Prognostic factors of stroke mortality rate, Cotonou 2013.

\begin{tabular}{|c|c|c|c|c|c|}
\hline Variables & Total & Death n (\%) & Gross RC & Adjusted RC & $p$ value \\
\hline \multicolumn{6}{|l|}{ Age (years) } \\
\hline$<50$ & 21 & $3(14.3)$ & 1 & 1 & \\
\hline$[50-60]$ & 29 & $2(6.9)$ & $0.44[0.07-2.93]$ & 0.38 [0.32 - 4.69] & 0.455 \\
\hline$[60-70]$ & 22 & $8(36.7)$ & $3.43[0.76-15.36]$ & 5.98 [0.99 - 35.97] & 0.051 \\
\hline$\geq 70$ & 28 & $16(57.1)$ & 8 [1.91 - 33.54] & 7.73 [1.49 - 39.99] & $0.015^{*}$ \\
\hline Marital status & & & & & $0.039^{*}$ \\
\hline Single & 38 & 17 (44.7) & 1 & 1 & \\
\hline Married life & 62 & $12(19.3)$ & $0.30[0.12-0.73]$ & $0.27[0.08-0.94]$ & \\
\hline Aphasia & & & & & $0.012^{*}$ \\
\hline No & 39 & $7(17.9)$ & 1 & 1 & \\
\hline Yes & 61 & $22(36.1)$ & $2.58[0.98-6.81]$ & $5.52[1.45-20.94]$ & \\
\hline
\end{tabular}

*Significant results.

scriptive and analytical aim. The method adopted clearly met the requirements of the type of study conducted. The calculated sample size was 96 and 100 stroke patients were eventually enrolled. However, the limit of this study is the non-identification with regard to the specific death causes. In fact, in Benin a doctor is not mandatorily bound to ascertain death occurrence, especially when it happens at home. Therefore, in this study, patients could have died as a result of stroke consequences or they could have lost their lives due to another disease.

Out of the one hundred (100) patients included in our study, 29 deaths occurred, meaning 29\% mortality rate in medium and long term. In fact, most of studies conducted in sub Saharan Africa in general and Benin in particular, focused on mortality during hospitalization period. Indeed Gnonlonfoun and et al. noted a global mortality rated $21.2 \%$ at Day-30 [6] in a study conducted on hyperglycemia at stroke acute stage in CNHU-HKM/ Cotonou. In the sub region, it was $24.8 \%$ in Senegal in 2010 [7]. On the other hand, in Libreville-Gabon that mortality during stroke acute stage was lower (9.5\%) [8]. Even in developed countries, mortality rate remains high. Thus in Spain, Felix-Redondo and et al. found out an inpatient mortality of $15.3 \%$ in a study conducted on "Ischemic stroke mortality tendency from 2000 to 2009) and prognostic factors" [9]. In the USA, in a recent study done by Maria Stepanova and et al. on "Recent Trends in Inpatient Mortality and Resource Utilization for Patients with Stroke in the United States: 2005-2009”, inpatient mortality rate decreased from $10.2 \%$ in 2005 to $9 \%$ in 2009 [10]. In Germany inpatient mortality rate is 6\% [11], in Corea $4.9 \%$ [12] and 3.9\% in Israel [13]. This variability in terms of inpatients mortality rate between developed nations and sub Sahara African countries could be explained by the difference in technical tray, and the colossal means made available by developed countries in view of stroke preventive and remedial coverage.

Within patients aged below 50, mortality rate was $14.3 \%$ whilst it was $57.1 \%$ within those aged beyond 70 . The increase in stroke mortality rate as per age is justifiable in the sense that natural mortality is correlated to age and more considerable beyond lifespan. Moreover, the combination of other co-morbidities is recurrent in old ages and this favors a higher mortality [14-16].

This study reveals that $57.1 \%$ of hemorrhagic stroke deaths in medium term occurred between 3 and 6 months and $28.6 \%$ occurred after one year. For ischemic stroke death classification as per time-limit is widely spread out. So, before 3 months period we noticed $27.3 \%$ ischemic stroke deaths, $22.7 \%$ deaths occurred within 3 - 6 months; $40.9 \%$ within 6 - 12 months. In reality our study did not cover stroke early mortality. The earliest death we recorded occurred one month after stroke incidence. It appears that among patients who survived short term and acute stage of stroke, mortality rate although considerable, knows a relatively noticeable decrease. Other authors also made the same remarks $[17,18]$. Nevertheless, Felix-Redondo in his study conducted in 2013 noticed $15.3 \%$ mortality during hospitalization, but that rate increased up to $16.9 \%$ in one year [9]. In fact, in his study Felix-Redondo considered overall mortality rate upon one year, whilst in ours we considered it in sequence. These results confirm medium and long term mortality decline, considering stroke after-effects. This could be explained by a fairly good management of identified risk factors and combating its complications. The lack of strength explains the $0 \%$ hemorrhagic stroke mortality within 6 - 12 months observed in our study. 
From the unvaried analysis, many factors came out as being associated with stroke medium and long term mortality. However, the multi-varied analysis enabled us identify prognostic factors associated with medium and long term stroke mortality in CNHU-HKM/ Cotonou. They are: age above 70 at stroke occurrence $\left(\right.$ IC $_{95 \%}=$ 7.73 [1.49 - 39.99], $\mathrm{p}=0.015)$, marital status $\left(\mathrm{IC}_{95 \%}=\right.$ 0.27 [0.08 - 0.94], $\mathrm{p}=0.039$ ) and the presence of aphasia at the occurrence of cardio-cerebral vascular disease $\left(\mathrm{IC}_{95 \%}=5.52\right.$ [1.45 - 20.94], $\left.\mathrm{p}=0.012\right)$.

With regard to age being prognostic factor of mortality, our results are comparable to other studies $[19,20]$. In fact, Mogensen in Copenhagen/Sweden in a study on "Cause-specific Mortality after Stroke: Relation to Age, Sex, Stroke Severity, and Risk Factors in a 10-Year Follow-up Study" in the year 2013 observed that old age increased by $1.05 \%$ stroke death risk [21]. Marital status is independently correlated with stroke mortality in medium and long term. In reality, patients living as couple are more protected than those living alone. This could be explained by the fact that those living in couple had more support from their spouse, receive more attention and care which strengthen them psychologically to combat the disease. To our knowledge, no research studied this association. In this study, the presence of aphasia during stroke occurrence is correlated with medium and long term mortality. These are factors which influence to a great extent psyches and could be causes of post-stroke depression.

\section{CONCLUSION}

Stroke mortality rate remains high even after patients discharge from hospital. Several factors account for such a high mortality. They are notably: old age, marital status and the presence of aphasia. Reducing the rate of stroke mortality in medium and long term will certainly depend on family support towards the victim and good coverage for aphasia.

\section{CONFLICT OF INTEREST}

The authors declare no conflict of interest.

\section{REFERENCES}

[1] Bejot, Y., Caillier, M., Rouaud, O., Benatru, I., Maugras, C. and Osseby, G. (2007) Stroke epidemiology: Impacts on therapeutic decision. La Presse Médicale, 36, 117-127. http://dx.doi.org/10.1016/j.lpm.2006.11.006

[2] Sene-Diouf, F., Basse, M., Ndao, K. and Ndiaye, M. (2006) Stroke functional prognosis in developing nations: Sénégal. Annales de Réadaptation et de Médecine Physique, 49, 100-104.

[3] Houinato, D., Avode, D.G., Adjien, C. and Kindjinou, M. (2005) Stroke epidemiological profile in hospitals in Co- tonoul. Le Bénin Médical, 29, 54-56.

[4] Avode, D.G., Djrolo, F., Houngbe, F., Attolou, V., Avimadje, M. and Addra, B. (1998) Death due to neurological complaints in CNHU Cotonou, Bénin. Médecine d'Afrique Noire, 45, 196-198.

[5] Mobonda Chimi, P.C., Touré, K., Sow, A., Seck, L.B., Diagne, N.S. and Ndiaye, M. (2013) Stroke pronostical and epidemiological aspects with elderly persons in neurology clinic of CHU de Fann, Dakar-Sénégal. Revue de Neurologie, 36, 75-96.

[6] Gnonlonfoun, D., Adjien, C., Kerekou, A., Ossou-nguiet, P.M, Agbetou, M. and Adoukonou, T. (2012) Hyperglycemia at acute stage of stroke in CNHU-HKM of Cotonou (BENIN). Revue du Cames Série A, 13, 59-62.

[7] Toure, K., Diagne, S.N., Seck, L.B., Sow, A.D., Ndiaye, M., Diop, M.S., Gueye, L. and Diop, A.G. (2010) prognostic factors of stroke mortality in neurological clinic of CHU de Fann, Dakar-Sénégal. African Journal of Neurological Sciences, 29, 15-18.

[8] Kouna-Ndouongo, P., Millogo, A., Siéméfo-Kamgang, F.P. and Assengone-Zeh, Y. (2007) Epidemiological features and outcome of stroke at libreville hospital (gabon). African Journal of Neurological Sciences, 26, 12-17.

[9] Félix-Redondo, F.J., Consuegra-Sánchez, L., RamírezMoreno, J.M., Lozano, L., Escudero, V. and FernándezBergés, V. (2013) Ischemic stroke mortality tendency (2000-2009) and prognostic factors. ICTUS Study-Extremadura (Spain). Revista Clínica Española, 213, 177-185. http://dx.doi.org/10.1016/j.rce.2013.01.005

[10] Stepanova, M., Venkatesan, C., Altaweel, L., Mishra, A. and Zobair, M. (2013) Recent trends in inpatient mortality and resource utilization for patients with stroke in the United States: 2005-2009. Journal of Stroke and Cerebrovascular Diseases, 22, 491-499.

http://dx.doi.org/10.1016/j.jstrokecerebrovasdis.2013.03. $\underline{005}$

[11] Heuschmann, P.U., Kolominsky-Rabas, P.L., Misselwitz, B., Hermanek, P., Leffmann, C. and Janzen, R.W.C. (2004) Predictors of in-hospital mortality and attributable risks of death after ischemic stroke. JAMA Internal Medicine, 164, 1761-1768. http://dx.doi.org/10.1001/archinte.164.16.1761

[12] Jung, K.H., Lee, S.H., Kim, B.J., Yu, K.H., Hong, K.S. and Lee, B.C. (2012) Secular trends in ischemic stroke characteristics in a rapidly developed country: Results from the Korean Stroke Registry Study (secular trends in Korean stroke). Circulation: Cardiovascular Quality and Outcomes, 5, 327-334. http://dx.doi.org/10.1161/CIRCOUTCOMES.111.963736

[13] Tanne, D., Koton, S., Molshazki, N., Goldbourt, U., Shohat, T. and Tsabari, R. (2012) Trends in management and outcome of hospitalized patients with acute stroke and transient ischemic attack: The National Acute Stroke Israeli (NASIS) Registry. Stroke, 43, 2136-2141. http://dx.doi.org/10.1161/STROKEAHA.111.647610

[14] Roger, V.L., Go, A.S. and Lloyd-Jones, D.M. (2012) Heart disease and stroke statistics 2012 update: A report from the American Heart Association. Circulation, 125, 200-220. 
[15] Towfighi, A. and Saver, J.L. (2011) Stroke declines from third to fourth leading cause of death in the United States: Historical perspective and challenges ahead. Stroke, 42, 2351-2355.

http://dx.doi.org/10.1161/STROKEAHA.111.621904

[16] Carandang, R., Seshadri, S. and Beiser, A. (2006) Trends in incidence, lifetime risk, severity, and 30-day mortality of stroke over the past 50 years. The Journal of the American Medical Association, 296, 2939-2946. http://dx.doi.org/10.1001/jama.296.24.2939

[17] Guliford, M.C., Charlton, J., Rudd, A., Wolfe, C. and Toschke, A.M. (2010) Declining 1-year case-fatality of stroke and increasing coverage of vascular risk management: Population based cohort study. Journal of Neurology, Neurosurgery \& Psychiatry, 81, 416-422. http://dx.doi.org/10.1136/jnnp.2009.193136

[18] Carter, K.N., Anderson, C.S., Hackett, M.L., Barber, P.A. and Bonita, R. (2007) Improved survival after stroke: Is admission to hospital the major explanation? Trend analysis of the Auckland regional community stroke studies. Cerebrovascular Diseases, 23, 162-168.

\section{http://dx.doi.org/10.1159/000097054}

[19] Kammersgaard, L.P., Jorgensen, H.S., Reith, J., Nakayama, H. and Pedersen, T.S. (2004) Short and long term prognosis for very old stroke patients. Copenhagen stroke study. Age Ageing, 33, 149-154. http://dx.doi.org/10.1159/000097054

[20] Calmels, P., Defay, C., Yvanes-Thomas, M., Laporte, S., Fayolle-Minon, I., Béthoux, F., Blanchon, M.A. and Gonthier, R. (2005) Is very old age a prognostic factor for outcome after a first stroke? Annales de Réadaptation et de Médecine Physique, 48, 675-681. http://dx.doi.org/10.1016/j.annrmp.2005.07.003

[21] Mogensen, U.B., Olsen, T.S., Andersen, K.K. and Gerds, T.A. (2013) Cause-specific mortality after stroke: Relation to age, sex, stroke severity, and risk factors in a 10-year follow-up study. Journal of Stroke and Cerebrovascular Diseases, 22, 59-65.

http://dx.doi.org/10.1016/j.jstrokecerebrovasdis.2012.04. $\underline{006}$ 